\title{
Electronic Democracy, Public Accountability and Public Service Information Provision
}

Each of the papers published in this third edition of the 2013 volume of Information Polity speaks to forms of informational relationships between governments and their citizens. The papers cover large swathes of the world, with contributions from the USA, Sweden, Portugal and Brazil, making this edition a truly international one in keeping with the continuing aspirations of this journal to inform its readers about a wide range of experiences in the field of digital government and democracy. Collecting together cases and ideas from many different countries offers a unique opportunity for scholarly and practitioner learning which, as editor, I am committed to fostering.

The first two papers here focus upon evidence and analysis about what has been happening with formalised developments in electronic democracy, the first from the USA and the second from Sweden. The paper from Donald Norris and Christopher Reddick, respectively from the Universities of Maryland and Texas, brings the Utopian enthusiasms of 'e-democracy' advocates down to earth with an enormous thump. Serving as a corrective they show how data from two separate surveys of local administrations [2006 and 2011] confounds the claims and expectations of the e-democracy zealots. Innovations are scarce, financial support for development is rare and there is little enthusiasm for formalised e-democratic development amongst the key actors at local levels, including citizens. Thus once the empirical world is assessed these authors argue that the normative world of advocacy looks extremely hollow both now and for the foreseeable future. The findings and argument of these authors run four-square with those from other published studies as they make clear. Indeed there is a good literature review to be found in this paper.

In his detailed study of supply of and demand for e-democracy in Sweden, Gustav Lidén, Post-doctoral Fellow at the Department of Social Sciences at Mid Sweden University, defines e-democracy as the use of information and communication technologies in democratic political processes concerning information, discussion and decision-making. He argues that e-democracy is the interplay of sufficient 'supply-side' opportunities for e-participatory activity by citizens and a demand-side where the citizenry is engaging through such tools. Lidén's findings point to the importance of educational attainment in both demand and supply equations and strikingly he argues that a mismatch can often occur, including in Sweden, between supply and demand; that is a mismatch that can be one of over-supply or one of unmet demand. The author also argues that neither gender nor age group work as explanatory variables in supply or uptake of e-democratic opportunity in Sweden.

But where do these first two papers leave those of us professionally interested in these matters? Could it be that formalised, 'artificial' projects designed to deliver enhanced forms of democratic involvement have little intrinsic significance to the mass of citizens - precisely that constituency at which they are aimed? Equally, could it be that informalised, spontaneous and extra-governmental modes of democratically-oriented electronic communications, by which I mean those afforded by social media, 
have much greater potential significance for citizens, as we continue to see from other research studies $[1,2]$ ?

I look forward to receiving papers that look more holistically at modes of e-democracy in our rapidly moving democratic landscapes.

The next two papers in this edition take us away from 'e-democracy' studies as defined above and into their vital hinterland, the exploration and understanding of governmental transparency. Neither of the papers above look at the question of how attempts to introduce enhanced democratic engagement in the form of e-democracy projects are based upon, or seek to augment, forms of transparency in government. Whilst e-democracy has its roots in the development of public participation in government we might ask what that participation is itself designed to achieve. Is participation a 'good' in itself or is it best regarded as a means to a democratic end, one that allows for 'see-through' or transparent government?

The first of these next two papers is authored by Greg Michener, Associate Professor from the Fundação Getulio Vargas in Rio de Janeiro, Brazil and Katherine Bersch from the Department of Government, University of Texas at Austin. Their contribution to our understanding of governmental transparency is considerable. Asking what we mean by the word they argue that we must understand not only the extent to which information released by governments is 'visible' but also the extent to which meaning can be clearly inferred from it. To achieve this understanding, they argue, we need to move away from the normative sphere by which so much of the academic and practitioner debate is characterised and towards the empirical. Once we define precisely what we mean by transparency, what it should look like in the world of practice, then we should test whether and to what extent it exists in practice. By setting out their bifurcated framework, visibility and inferability, and by analysing each of these concepts separately and in detail, Michener and Bersch invite the next scholarly step, that of empirical work that will help index the extent of transparency in any governmental system. In keeping with their thesis Michener and Bersch write with exemplary clarity. Their paper is utterly transparent in each of their meanings.

The second of these papers on transparency is from Rui Pedro Lourenço of the Faculty of Economics at the University of Coimbra, Portugal. Interestingly, though necessarily limiting the scope of the paper, the author looks at transparency in the specific context of the open data movement and is therefore concerned with transparency as it applies to 'structured data'. Lourenço is concerned too with the role of 'information brokers', those who make sense of released data sets to make them, in the words of Michener and Bersch [but not of Lourenço], visible and inferable. Ultimately, the author is concerned to establish a comprehensive data disclosure strategy in relation to released data-sets, in part by testing ideas against the Portuguese case. The author warns that simply disclosing datasets may not address a true transparency strategy.

As Editor I am hopeful that, by bringing these papers together, this journal can inspire more empirical investigations of the kind that Michener and Bersch call for and which, albeit within a limited framework, Lourenço has set out to achieve. So too with the following paper.

Finally, in this edition, we come to a paper authored by Liziane A. da Silva, Saulo Magnus, Milene S. Silveira and Cristiano Maciel from various institutions in Brazil, as set out in the paper itself. Their paper links with the previous two papers as the authors discuss efforts in Brazil to improve citizen contact by the Brazilian government through information about its services made available online. The authors are concerned with Michener and Bersch' 'visibility' and 'inference', arguing that information must be easy to locate and access, and readily understood. These authors focus upon extant online help systems designed to deliver on this Brazilian approach to transparency. Most interesting is these authors' approach to 'crowdsourcing' these help systems. They argue from survey evidence that existing 
recommendations for help systems do not contain enough information. They recommended a set of guidelines for their construction which, when presented to representatives from target populations of such websites - citizens, system developers and professionals from the e-GOV area - brought about major improvements. Here too, therefore, we have a most interesting contribution to the delivery of more transparent government.

JA Taylor,

Editor-in-Chief, Information Polity.

E-mail: J.Taylor@gcu.ac.uk

September, 2013.

\section{References}

[1] P.N. Howard and M.M. Hussain, Democracy's Third Wave: digital media and the Arab spring. Oxford: Oxford University Press, 2013.

[2] M. Castells, Networks of Outrage and Hope: social movements in the internet age. Cambridge: Polity Press, 2012. 